\title{
The Meaning of Mood - Embedded Clauses in Spanish as a Case in Point
}

\begin{abstract}
Mental space theory is a cognitive framework that explains the interpretation of linguistic expressions: it explains how interlocutors get from input to output. Whereas in traditional semantics words are taken to possess a static, prefabricated meaning, cognitive frameworks take meaning to be the result of an interpretive process.

This article explains how mental space theory can be used in an analysis of mood in embedded clauses in Spanish. It starts from the assumption that the meaning of mood is constructed by interlocutors in an interpretive process on the basis of information from the modal morphemes combined with information from the linguistic as well as the extra-linguistic context. The interpretive process is represented as a sequence of mental spaces which are linked and structured on the basis of information from language and context.
\end{abstract}

\section{Introduction}

When I first started my PhD on the establishment of reference in Spanish noun phrases, I needed a theoretical framework with a notational system in which I could make explicit the conceptualisation of noun phrases. I discussed this with my supervisor, Torben Thrane, and he suggested Fauconnier's mental space theory.

The theoretical advantage of the theory of mental spaces is that it explains the interpretation of linguistic expressions, that is, the process rather than the product of the process, and it is therefore appropriate for representing how meaning is established in an interpretive process on the basis of information from linguistic expressions. The theory of mental spaces has been widely used as a framework for explaining how meaning is established on the basis of various linguistic expressions such as pronouns, aspect and modal forms.

It is the aim of this paper to explain the meaning of mood in embedded clauses in Spanish in the perspective of the theory of mental spaces.

It is assumed that the meaning of mood is established in an interpretive process on the basis of information from the modal morphemes and the context in which they occur. A sketch of how this claim can be substantiated is given by an analysis of a selected number of examples.

\section{Mood as a grammatical category}

In Spanish, mood is one of the three inflectional forms of the verb: tense, aspect and mood. Each of these forms specifies a particular dimension of the situation established by the verb. It is a basic premise of this paper that mood provides information about how situations are linked in space. Before explaining this point, I will briefly address mood: its characteristics and how it has been described in the literature.

Spanish inflects for the indicative, the subjunctive and the imperative, and mood distinctions can be made both in independent clauses and in all three kinds of subordinate clauses: embedded

\footnotetext{
* Helle Dam-Jensen

Department of Business Communication

Aarhus University

Business and Social Sciences

Fuglesangs Alle 4

DK-8210 Aarhus $V$

hed@asb.dk
} 
clauses, relative clauses and adverbial clauses. Unlike independent clauses, subordinate clauses only allow the indicative and the subjunctive. The use of one or the other form depends on the meaning of the superordinate clause. For instance, expressions of emotion only allow the subjunctive in the embedded clause, whereas expressions of security only allow the indicative in the embedded clause, as exemplified in (1)-(2).

(1) Me alegra que puedas ${ }_{(\text {subj) }}$ venir.

'I am happy that you can come.'

(2) Es seguro que vas $\underline{\text { (ind) }}_{\text {a venir. }}$

'It is certain that you will come.'

The fact that some superordinate expressions are compatible with only one or the other modal form has led to the widespread view that mood is a question of government. However, the mood system is far more complicated than mere government as many subordinate clauses, including embedded clauses, allow double selection, as shown by the following examples:

$\left(3^{\mathrm{a}}\right)$ Dice que vienen ${ }_{\text {(ind) }}$.

'He says that they will come.'

(3b) Dice que vengan (subj) .

'He says that they must come.'

(3a) and (3b) show that superordinate clauses with verb phrases headed by decir can combine with both the indicative and the subjunctive, depending on the meaning that the speaker wants to convey. As mood in Spanish seems to be subject to (semantic) government in some cases and to speakers' selection in others, an explanation of mood must be sought that explains the connection between the expressions of so-called government and those of double selection. I will argue, along with others, that such an account takes its starting point in the semantics of mood.

\section{The semantics of mood}

With a starting point in Thrane (1998), this article assumes that situations established by verbs in the indicative are always located in time and space. No matter whether the situation is described by the superordinate expression as being guaranteed or felt, as exemplified by (4) and (5) below, the situation has the same basic meaning: it has existence in time and space, and can as such be characterised as factual (see section 5).

(4) Les garantizo que el Gobierno no $\underline{\mathrm{va}}_{\text {(ind) }}$ a presionar.

'I guarantee you that the Government will not put on pressure.'

(5) Lo que sucede con el obeso es que siente que no tiene $\underline{\text { (ind) }}_{\text {control sobre nada. }}$

'What happens with the obese person is that he feels that he does not have anything under his control.'

(examples extracted from REA - CREA)

By contrast with the indicative, the meaning of the subjunctive is harder to determine, as demonstrated by example (1) above, repeated below as (6), and (7)-(8).

(6) Me alegra que puedas ${ }_{(\text {subj) }}$ venir.

'I am happy that you can come.'

(7) Hay muchos que esperan que caigan $\underline{\text { subj) }}_{\text {. }}$.

'There are many that hope that they will fall.'

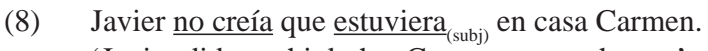

'Javier did not think that Carmen was at home.'

(6) establishes a situation which has already come into existence, 'you can come'. The situation established by (7), on the other hand, has not yet come into existence but is merely hoped for. (8) 
does not carry information as to whether the situation of the referent of Carmen being at home is a fact or not. The use of the subjunctive merely shows the speaker's lack of belief that the situation is a fact (see section 5 for a more detailed analysis).

Various studies have striven to formulate a general meaning of the subjunctive which can explain its diversity of meaning. RAE (1973) sums up the main traditional viewpoints on the semantics of mood in Spanish. The account (1973: 353) takes its starting point in the distinction between dictum and modus, between what is said and the "subjective attitude" (la actitud subjetiva), the attitude of the speaker towards this. The modal forms are one of the means that language provides for expressing modus. When the indicative is used, the verbal action is conceived as being real or not real (depending on negation), and when the subjunctive is used, the verbal action is not regarded as real (1973: 454).

The idea that mood reflects the speaker's attitude towards the content of the sentence goes back as far as Salvá (1830) (Manteca Alonso-Cortéz 1981: 13), and the reality/non-reality distinction is generally used in grammar books, in different variations (e.g. Togeby 1963, RAE 1973, Alarcos Llorach 1994, Gili Gaya 1994).

One of the first attempts to give a more meticulous account of mood in Spanish is Terrell/Hooper (1974). They suggested the distinction between assertion/non-assertion with a starting point in Lenz (1944), among others, who associated mood with semantic concepts such as assertion and presupposition. Their theory can be seen as a reaction to structuralist and transformational theories, which generally took mood to be a question of government (a view that is basic to many descriptions of mood, as mentioned above). The assertion/non-assertion distinction has formed the basis of the major part of research in mood in Spanish (see for example Travis 2003, Mejías-Bicandi 1994, 1998a, 1998b and Gregory 2001).

To assert something means to attribute something with a truth-value. In this sense, assertion refers to real-world situations. According to the assertion theory, mood depends on the truth of the proposition of the embedded clause: the indicative reflects assertion, whereas the subjunctive does not. Although the assertion theory captures the main characteristics of the indicative and the subjunctive, it cannot be generalised to all types of embedded clauses.

First of all, it is a problem that a subordinate clause does not convey the necessary information for creating an assertion. It is the sentence as a whole which creates assertion, not the subordinate phrase, which merely contributes to the assertion. In the case of embedded clauses subordinated to expressions of perception and communication, this problem is overcome by introducing what Terrell and Hooper call 'reported assertion' (Terrell/Hooper 1974: 486), thereby reckoning on two types of assertions for this sentence type:

1. The assertion made by the speaker on the basis of the content of the sentence as a whole.

2. The assertion made by the referent of the subject of the superordinate expression on the basis of the content of the embedded clause.

This locates the assertion of the embedded clause at a secondary level at which it depends on the assertion of the whole sentence. This provides assertion with explanatory value in embedded clauses subordinate to expressions of perception and communication, but it cannot be generalised to all contexts. Nor can it be extended to relative clauses and adverbial phrases, as neither can be said to establish a proposition that can be attributed a truth-value. So an explanation in terms of assertion cannot be generalised to all modal contexts.

Furthermore, Terrell/Hooper (1974: 488) note that a group of embedded clauses which cannot be explained by the assertion theory are those which are subordinate to either mental comment predicates (9) or mental act predicates (10), as neither can be said to express an assertion.

(9) Lamento que la posición del gobierno sea $\underline{\text { (subj) }}_{\text {Legativa. }}$

'I regret that the position of the government is negative.' 
(10) Se dieron cuenta de que no tenían ${ }_{\text {(ind) }}$ infraestructura suficiente.

'They realised that their infrastructure was insufficient.'

(examples extracted from REA - CREA)

Expressions of mental act and comment have in common that they imply presupposition: they presuppose the existence of a situation. However, they behave differently with regard to mood. Mental act predicates, as in (10), combine with the indicative. Under the assertion hypothesis one would have expected a meaning in terms of assertion, but carrying both a presupposition and an assertion is a contradiction in terms. However, it has been suggested that there is a difference between the presupposition of sentences such as (9) and (10) (Hooper 1973; Terrell 1975). The presupposition of (9) is strong because the truth of the proposition of the embedded clause holds good despite both negation and questioning. The presupposition of (10), on the other hand, is weak. This is due to the fact that embedded clauses of darse cuenta ('to realise') do not necessarily establish situations whose truth is presupposed, as shown by (11).

(11) No se dieron cuenta de que no $\underline{\text { tuvieran }}_{(\text {subj) }}$ infraestructura suficiente.

'They did not realise that their infrastructure was insufficient.'

(10) and (11) differ in negation and inflection for mood. The use of the indicative in (10) shows that the infrastructure was in fact insufficient. The use of the subjunctive in (11), on the other hand, shows that the infrastructure may or may not be sufficient. The embedded clause of (11) is therefore not presupposed to be true. This shows beyond any doubt that there is a difference between the presuppositions established by mental act and comment predicates respectively, but I will claim that the explanation is only partial. In section 6 , it is argued that a more substantial explanation can be given with a starting point in information structure, as suggested by Mejías-Bikandi (1994, 1998a and 1998b) and others.

Apart from the fact that the assertion theory cannot be generalised to all modal contexts, one main objection to the framework is that it is based on truth-conditional semantics, in which propositions are claimed to be true or false. This means that linguistic expressions acquire meaning by virtue of the fact that they correspond to objects in the world. Such a framework prevents us from explaining linguistic expressions which are not necessarily true with respect to the real world, for example because they do not describe entities or situations which actually exist or because properties assigned to entities do not correspond to reality (Fauconnier 1994: 15). In this paper it is argued that a cognitive framework has a greater explanatory value. In such a framework, meaning is constructed individually by interlocutors on the basis of linguistic expressions, context and background knowledge. This allows us to account for aspects of meaning which cannot be accounted for in the realm of truth-conditional semantics. In this sense, it does not matter whether propositions are true with respect to the real world or not.

Mental space theory is a cognitive framework that explains the interpretation of linguistic expressions, how interlocutors get from input to output. The following section explains how mental space theory can be used in an analysis of mood.

\section{Mental space theory}

It is a basic premise of mental space theory that meaning is constructed mentally by interlocutors on the basis of information from linguistic expressions in combination with information from context. This process is represented as a sequence of mental spaces which are linked and structured on the basis of information from language and context. Thus, the theory is a dynamic framework for explaining the way in which interlocutors establish cognitive links between mental representations established on the basis of information from language and context.

In the introductory note to Mental spaces, Fauconnier makes the observation that "Relatively simple grammatical structures give instructions for space construction in context" (Fauconnier: 1994: 2). This statement makes at least three points. 
First, language provides information for an interpretive process. This suggests that meaning is not static, but is taken to be established dynamically by interlocutors in an interpretive process.

Second, grammatical items guide this process by virtue of being instructional. This means that grammatical items are cues that guide the interpretive process ${ }^{1}$. In this article, it is furthermore argued that it is a main characteristic of grammatical items, as opposed to lexical items, that their meaning is stable and univocal: each grammatical item only has one meaning which may have different, although related nuances, depending on context. In the words of Thrane (1997: 238):

"The semantic effect that a linguistic item has in virtue of being a carrier of meaning is always the same.”

Third, the interpretation depends on context. This means that the meaning of linguistic expressions is undecidable per se, and is created with appeal to the linguistic context as well as to the extra-linguistic context. In this paper, it is assumed that linguistic and extra-linguistic context differ in nature in that the former contributes in a systematic way to interpretation, due to its conventional nature (see for example Thrane 1997 and Dam/Dam-Jensen 2007 for a more detailed account of meaning), whereas extra-linguistic context does not contribute systematically, as it may originate from an infinite number of sources (Dam/Dam-Jensen 2007: 91-93). In short, meaning can be said to be constructed in a hermeneutic circle in which the interpretation of each linguistic expression depends on that of the whole of which it forms part; but at the same time, the interpretation of the context depends on the interpretation of the constituent parts.

\section{Mental spaces and the semantics of mood}

Mejías-Bikandi (1998a: 109) takes mood to be a marker that controls the flow of information between spaces. The indicative allows a connection to the speaker's reality space, but the subjunctive does not.

On the basis of the points made above about grammatical items having a univocal instructional meaning, the following instructional values are suggested for the indicative and the subjunctive (slightly reformulated from Dam/Dam-Jensen 2010: 126):

- Indicative: Locate the situation created by the verb phrase relative to reality space.

- Subjunctive: Do not locate the situation created by the verb phrase relative to reality space.

As illustrated above (examples (6)-(8)), embedded clauses in the subjunctive can be subordinate to expressions which generate a greater variety of meaning than the indicative: the subjunctive can be used in both factual and non-factual contexts. To account for this general meaning, its instructional value is formulated as the "negative" counterpart of the indicative. In order to decide the exact shape of the situation described, it is necessary to appeal to context. It must therefore be the indicative which is the marked form and the subjunctive which is unmarked (contrary to what is traditionally presumed (Bosque 1990: 29)).

Let us take a closer look at what it means to locate a situation relative to reality space. It is a basic premise of mental space theory that linguistic expressions create mental representations. 'Situation', therefore, does not refer to a situation of real life, but to speakers' mental representations generated on the basis of linguistic expressions. Reality space, in turn, is also a mental representation, speakers' mental representation of reality (Fauconnier 1994: 15), which accounts for their background knowledge or knowledge of the world. This space is therefore the so-called origin space relative to which the interpretive process unfolds. Consequently, to locate a situation relative to reality space is to establish a mental connection between the situation and reality space and to regard this situation as valid relative to this space.

1 Lexical items can also be characterised as being instructional: On receiving a token of a word type, the addressee is instructed to activate his concept attached to that word. Lexical meaning is therefore also instructional (Dam/DamJensen 2007: 86-87). See also Harder (2007) and Thrane (1997) for a detailed account of instructional meaning. 
The interpretive process is prompted by an utterance. The situation in which this takes place is called the utterance situation. Apart from the location of the speaker, an utterance situation contains the location of the addressee. Its dimensions are determined by the volume of the utterance. In Figure 1 below, the utterance situation is depicted after Thrane (1980: 192-194): A is the speaker, B the addressee, and the dots are the objects of discourse or what is talked about. The fact that speakers may talk about both things which form part of the utterance situation (objects which are actually there) and things which do not is represented by the dots being outside or inside the marked space of the utterance situation.

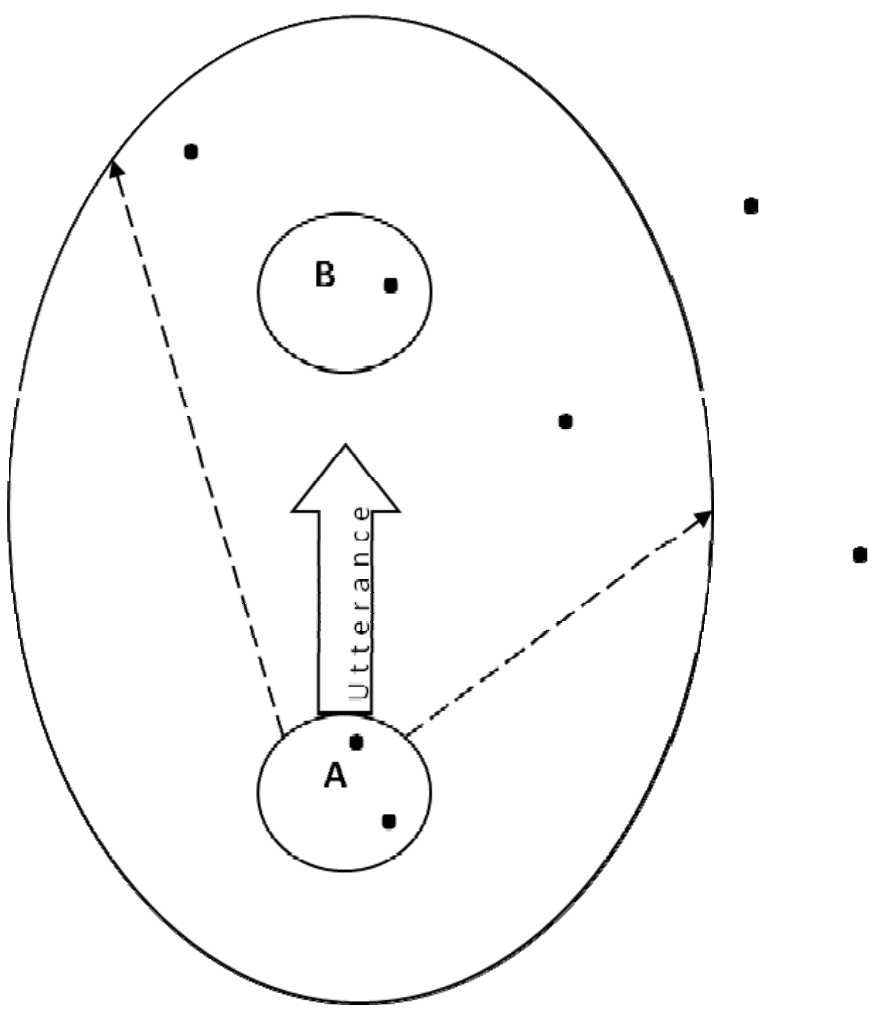

Figure 1. Utterance situation (Thrane 1980: 194)

The nature of the utterance situation forms part of speakers' conception of reality, or reality space.

These theoretical assumptions can now be applied in analysis. The verb phrase of the following example appears in the indicative, which prompts the construction of a situation connected to reality space.

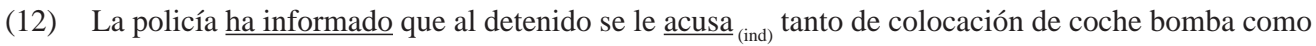
del tiroteo en la isla.

'The police have stated that the person under arrest is charged ${ }_{\text {(ind) }}$ with both placing a car bomb and the shooting on the island.'

(extracted from el País, 23/07/11)

In (12), the verb phrase, ha informado instructs the addressee to locate the established situation relative to his reality space. Locating a situation relative to reality space means that the situation exists in time and space, so it is a factual situation (see section 3). As mentioned above, the indicative only carries information for the construction of factual situations.

The verb phrase of the next couple of examples (a repetition of (7) and (9) above) appears in the subjunctive and therefore does not create a link to reality space. 
(13) Hay muchos que esperan que caigan $\underline{\text { (subj) }}_{\text {. }}$

'There are many that hope that they will fall.'

(14) Lamento que la posición del gobierno sea $\underline{\text { (subj) }}_{\text {negativa. }}$

'I regret that the position of the government is negative.'

In both (13) and (14), the subjunctive instructs the addressee not to connect the situation established relative to reality space. The exact interpretation of what this means differs depending on the context. In (13), the meaning of the verb phrase of the superordinate clause, esperan, implies that the situation described in the embedded clause has not yet come into existence: it does not exist in time and space, it is non-factual. In (14), on the other hand, the meaning of the verb phrase of the superordinate clause, lamento, does not imply that the situation of the embedded clause is non-existent. Quite the opposite, it is already there: lamentar is a factive verb in the sense of Kiparsky/Kiparsky (1971), and as such it presupposes the existence of a situation. This is why the addressee is not instructed to create a link to reality space - it has already been established.

The analysis of for example lamentar in terms of presupposition is sometimes challenged by referring to sentences such as (15) below, used to pass on new information to the addressee ${ }^{2}$.

(15) Lamento tener que despedirle.

'I am sorry that I have to fire you.'

The question that arises as a consequence of (15) is how it can be used to transfer new information even though lamentar carries a presupposition. The answer to the question lies in the semantics-pragmatics distinction. The information that the speaker wants to convey to the addressee is that he is being fired, but by presupposing this information and thereby presenting something different as the new information (lamento), the speaker downplays the presumed seriousness of the information. In this sense, it is the semantics, the language system, which forms the basis for the way we interpret language in use.

A different group of verbs that deserves an explanation with a starting point in the suggested values are verbs of communication and perception, such as the semi-factive verb creer ('think'). When these verbs are un-negated, they typically appear in the indicative (16), whereas they can appear in both the subjunctive (17) and the indicative (18) if they are negated.

(16) Javier creía que estaba ${ }_{\text {(ind) }}$ en casa Carmen.

'Javier thought that Carmen was at home.'

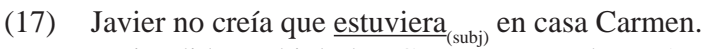

Javier did not think that Carmen was at home.

(18) Javier no creía que estaba ${ }_{\text {(ind) }}$ en casa Carmen.

'Javier did not think that Carmen was at home.'

In (16), we will say that the situation established by the embedded clause is interpreted as being a situation which is assumed by the speaker to be true. Translated into mental space terms, a situation is created which, according to the speaker, is located relative to reality space. In (17), on the other hand, the addressee is not instructed to locate the situation of the embedded clause relative to reality space. The sentence does not carry information as to whether the situation is factual or not: this may or may not be the case. The use of the subjunctive merely shows the speaker's lack of belief that the situation was a fact. In (18), on the other hand, the superordinate clause carries the information that the speaker at some point in the past did not believe that the situation of the embedded clause was a fact. However, the use of the indicative of estaba shows that this situation was in fact factual: the referent of Carmen was at home.

2 I would like to thank Professor Henning Nølke for pointing this out to me. 
With regard to the interpretation of the indicative in terms of reality, it could be objected that verb phrases in the future tense of the indicative ${ }^{3}$ do not establish situations in time and space because from the perspective of the utterance situation they have not yet taken place and therefore do not generate a factual interpretation. However, in the context of this study, it will be assumed that the future instructs the addressee to establish a situation which according to the speaker will take place after the time of utterance (Jensen 2002: 4). This can be explained by considering the following three examples.

(19) Dice que Lucas vendrá (future) $^{\text {. }}$

'He says that Lucas will come.'

(20) Dice que Lucas va $\underline{\text { (present of ind) }}$ a venir. 'He says that Lucas will come.'

(21) Duda que venga $\underline{\text { (present of subj) }}_{\text {Lucas. }}$ 'He doubts that Lucas will come.'

None of the verb phrases in the embedded clauses of these three examples establishes a situation which coincides with the utterance situation. In (19), the verb phrase of the embedded clause instructs the addressee to establish a situation posterior to the utterance situation in which the referent of Lucas, according to the speaker, will come. This situation is understood as a prediction. In (20), the verb phrase of the embedded clause is a verbal periphrasis in which the finite verb appears in the present tense. The addressee is therefore instructed to construct a situation in which the referent of Lucas comes: in the utterance situation there are indications that this is true. Both (19) and (20) establish a situation which is located in time and space. In (21), on the other hand, the verb phrase of the embedded clause does not establish a situation located in time and space because the verb dudar describes a situation whose existence is unsure.

The next section explains this interpretive difference with reference to information structure.

\section{Mood and information structure}

Both Mejías-Bikandi (1998b) and Gregory (2001) explain mood as a difference in information. According to Mejías-Bikandi (1998b: 947), the indicative presents new information, whereas the subjunctive presents either old information or untrue situations.

As we have just seen, sentences with the subjunctive with a factual interpretation carry a presupposition. So they do not provide new information, and in this sense they are not informative per se. The addressee must search for this elsewhere, and the place to look is in the superordinate clause, the speaker's evaluation of the situation described in the embedded clause. This presents new information.

We saw above that it is not only factive verbs (or comment predicates) that carry a presupposition, but also mental act predicates. The problem is, though, that mental act predicates appear with the indicative, whereas comment predicates appear with the subjunctive. This modal difference can be explained by information structure. The lexical meaning of comment predicates presupposes that the addressee has previous knowledge of the situation in the embedded clause, whereas this is not the case with mental act predicates, which will always present the situation of the embedded clause as new information. Both predicate types carry a presupposition of existence, but not of knowledge.

In (9) and (15) above, the verb lamentar presupposes that the addressee has previous knowledge of the position of the government. This is old information. In (10), on the other hand, darse

3 The future tense is not used in the subjunctive in modern Spanish, apart from in very specialised contexts, such as in legal language. 
cuenta does not presuppose that the addressee has previous knowledge of this situation. The difference in presupposition is a difference in knowledge. In mental space terms, this is a difference between the content of the reality space of the speaker and the addressee, that is, a difference between the background knowledge of the speaker and that of the addressee (compare section 5).

\section{Generalisation of the analysis - a sketch}

At the beginning of this presentation I set out to substantiate the assumption that mood is a question of connection/non-connection to reality space. A thorough analysis would require confrontation with independent clauses as well as with adverbial and relative clauses. With regard to adverbial and relative clauses, one would have to take into account the fact that the three kinds of subordinate clauses represent different kinds of subordination and therefore generate a different interpretation of the established situation and its relation to the superordinate situation.

Whereas embedded clauses establish a situation which is characterised by a superordinate situation created by a superordinate expression, adverbial clauses establish a logical relation relative to the situation established by the superordinate expression, e.g. of time, cause or consequence. For example, adverbial clauses introduced by a conjunction of time can either establish a situation which is prior to or coinciding with the situation established by the superordinate expression, thereby creating a link to reality space. However, they may also establish a situation which is subsequent to the situation of the superordinate expression.

The nature of dependency of relative clauses to the superordinate expression differs from that of adverbial clauses and embedded clauses in that they are complements of nominal constituents. The result is that relative clauses establish a property of the entity created by the nominal constituent. When the verb phrase of a relative clause appears in the indicative, the entity of the nominal constituent is conceptualised as existing in a factual situation (reality space), set up by the relative clause. If the verb phrase appears in the subjunctive, on the other hand, the entity of the nominal constituent is set up in a situation which is not connected to reality space: the entity does not exist in a factual situation.

As indicated above, it is a basic premise of this work that the meaning of a grammatical item is always the same. As both the indicative and the subjunctive can be used in a variety of contexts, their instructional values, in particular in the case of the subjunctive, are formulated in very general terms. An analysis in terms of these values therefore works at a high level of abstraction. On the one hand, one result of this is that they do not have a very high degree of testability in the sense of Popper (1959). In order for falsification and prediction to take place, these general values could be spelled out in more concrete values deduced from the general ones. On the other hand, however, the instructional values provide the language user with a basis for explaining instances of the indicative and the subjunctive which, on the face of it, could look like different uses of the same modal form. This will provide a methodologically uniform basis for the explanation of the way the two modal forms can be used.

It should be noted that while the explanation suggested in this paper may be operational for mood in Spanish, it cannot be generalised to French, for example. I will not expand on the differences in the use of mood in the two languages, but merely give a couple of illustrative examples. In Spanish, embedded clauses subordinated to the noun idea often appear in the subjunctive. This is not the case in French, where idée generally combines with the indicative, as shown by Jønsson (2011). Furthermore, the subjunctive can only be used after dire if it appears in the imperative, as opposed to Spanish (compare for example ( $\left.3^{b}\right)$ above).

Summing up, there are still loose ends that remain to be addressed, which can strengthen and refine the assumptions presented above. To increase the testability of the instructional values, they can be translated to a lower level of abstraction. On this basis, the values can be tested 
against a more substantial amount of data - not only embedded clauses, but also adverbial and relative clauses. Lastly, comparative studies can be conducted of the use of mood in Spanish and in French, for instance. This could help refine the basic assumption of factuality presented in this article.

\section{Concluding remarks}

Based on the account of mood suggested in this article, grammatical items provide univocal and constant information as an input to the interpretive process of the addressee. Such an account obeys the principles of generalisation of the object of study and uniformity in its analysis. It is argued that the indicative instructs the addressee to locate the situation established by the verb phrase relative to reality space. In the case of the subjunctive, the addressee is instructed not to create a link to reality space. The fact that the subjunctive is formulated as the "negative counterpart" of the indicative has the effect that its instructional meaning is very general. As a consequence, many contextual clues are required in order to reach a precise interpretation.

It was argued in the introduction that mental space theory is an appropriate framework for representing the dynamic nature of meaning: words do not come with a static, prefabricated meaning - instead, meaning is the result of an interpretive process.

I would like to conclude with a quote that can be said to encapsulate the basic principle behind this paper:

"So, to conclude, it has been my aim to substantiate a claim that meaning does something - in fact that it provides the information in terms of which mental models are constructed, manipulated and searched. And if you feel that what I've said has done something to you, I may have succeeded!” (Thrane 1997: 249).

\section{References}

Alarcos Llorach, Emilio 1994: Gramática de la lengua Española. Madrid: Editorial Espasa Calpe, S.A.

Bosque, Ignacio 1990: Las bases gramaticales de la alternancia modal. Repaso y balance. In Bosque, Ignacio (ed), Indicativo y subjuntivo. Madrid: Taurus Universitaria, 13-65.

Dam, Lotte/HDam-Jensen, Helle 2007: "Instructions, context and compositionality: How to combine functional, lexical and interpretive dimensions of meaning”. In Boye, Kasper (ed.), Language and Comprehension: Input, Process, Product [Acta Linguistica Hafniensia, vol. 39]. Copenhagen: Reitzels Forlag, 83-100.

Dam, Lotte/Dam-Jensen, Helle 2010: Mood in complementizer phrases in Spanish. How to assess the semantics of mood. In Pragmatics \& Cognition 18(1), 111-135.

Fauconnier, Gilles 1994: Mental spaces. Cambridge: Cambridge University Press.

Gili Gaya, Samuel 1994: Curso Superior de Sintaxis Española. Barcelona: Bibliograf.

Gregory, Amy E. 2001: A cognitive map of indicative and subjunctive mood use in Spanish. In Pragmatics and Cognition 9-1, 99-133.

Harder, Peter 2007: Shaping the interactive flow. Language as input, process and product. In Boye, Kasper (ed.), Language and Comprehension: Input, Process, Product [Acta Linguistica Hafniensia, vol. 39]. Copenhagen: Reitzels Forlag, 7-36.

Jensen, Kjær 2002: Condicionar. El futuro y el condicional en el sistema verbal español moderno. Paper presented at the XV Skandinaviske Romanistkongres. In Romansk Forum 16(2), 1-11.

Jønsson, Mads 2011: Grammaire nominale et la complétive adnominale - une analyse modulaire. Unpublished PhD dissertation, SLK, Faculty of Arts, Aarhus University.

Kiparsky, Paul/Kiparsky, Carol 1971: Fact. In D. Steinberg/Jakobovits, A. (eds.), Semantics. An interdisciplinary reader in philosophy, linguistics and psychology. Cambridge: Cambridge University Press, 345-369.

Lenz, Rodolfo 1944: La oración y sus partes. Santiago, Chile: Editorial Nascimento.

Manteca Alonso-Cortés, Angel 1981: Gramática del subjuntivo. Madrid: Ediciones Cátedra.

Mejías-Bikandi, Errapel 1994: Assertion and Speaker’s Intention: A Pragmatically Based Account of Mood in Spanish. In Hispania 4(77), 892-902. 
Mejías-Bikandi, Errapel 1998a: Syntax, discourse and acts of the mind: a study of the indicative/subjunctive contrast in Spanish (dissertation). University of California, San Diego.

Mejías-Bikandi, Errapel 1998b: "Pragmatic presupposition and old information in the use of the subjunctive”. In Hispania: a journal devoted to the interests of the teaching of Spanish and Portuguese. 81, 941-948.

Popper, Karl R. 1959: The Logic of Scientific Discovery. London/Melbourne/Sydney/Auckland/Johannesburg: Hutchinson.

RAE: Real Academia Española 1973: Esbozo de una Nueva Gramática de la Lengua Espanõla. Madrid: Espasa Calpe. Terrel, Tracy/Hooper, Joan 1974: A semantically based analysis of mood in Spanish. In Hispania 57, 484-494.

Terrell, Tracy D. 1975: Assertion and Presupposition in Spanish Complements. In Luján, Marta/Hensey, Fritz (eds.), Current Studies in Romance Linguistics. Washington D.C.: Georgetown UP, 221.245.

Thrane, Torben 1980: Referential-semantic analysis. Cambridge: Cambridge University Press.

Thrane, Torben 1997: Understanding Semantics. In Bache, Carl/Klinge, Alex (eds.), Sounds, Structures and Senses. Odense: Odense Universitetsforlag, 235-250.

Thrane, Torben 1998: Nominaler, nominaliseringer og semantisk kompleksitet. In Hermes 21, 39-66.

Togeby, Knud 1963: Mode, aspect et temps en espagnol. Copenhagen: Det Kongelige Danske Videnskabernes Selskab, 34(1).

Travis, Catherine 2003: The semantics of the Spanish subjunctive: Its use in the natural semantic metalanguage. In Cognitive Linguistics 14(1), 47-69. 